\title{
Erratum to: Online knowledge sharing mechanisms: A systematic review of the state of the art literature and recommendations for future research
}

\author{
Yeganeh Charband $^{1} \cdot$ Nima Jafari Navimipour ${ }^{1}$
}

Published online: 4 September 2017

(C) Springer Science+Business Media, LLC 2017

Erratum to: Inf Syst Front (2016) 18:1131-1151

https://doi.org/10.1007/s10796-016-9628-Z

The original version of this article unfortunately contained mistakes in references. The correct version is presented below. (Ain Baig, Khan, \& Chaudhry, 2014)

Ain Baig, N. u., Khan, A. W., \& Chaudhry, B. (2014). Role of Demographic Diversity in Online Knowledge Sharing. Pakistan Journal of Commerce \& Social Sciences, 8(2)279-304.

The online version of the original article can be found at https://dx.doi. org/10.1007/s10796-016-9628-Z

Nima Jafari Navimipour jafari@iaut.ac.ir

1 Young Researchers and Elite Club, Tabriz Branch, Islamic Azad University, Tabriz, Iran 